\title{
Microwave, Ultrasound Assisted Dyeing- Part I: Dyeing Characteristics of C.I. Disperse Red 60 on Polyester Fabric
}

\author{
Morsy A. El-Apasery*, Rehab A. Abdelghaffar, Mona M. Kamel, Magda M. \\ Kamel, Badria M. Youssef and Karima M. Haggag \\ Dyeing, Printing and Textile Auxiliaries Department, Textile Research Division, \\ National Research Centre, 33 El Buhouth St., Dokki, Cairo, Egypt.
}

\begin{abstract}
7 HE GOAL of this study was to utilize microwave and ultrasound irradiation as green methodologies, not only to improve dyeing performance of polyester fabric with disperse red 60, but also, to save energy for preserving the environmental impact. Both of color strength expressed as dye uptake and the fastness properties of the dyed fabric were evaluated.
\end{abstract}

Keywords: Microwave technique, Ultrasound technique, Dyeing, Disperse dyes and Polyester fabric.

\section{Introduction}

Textile wet processing needs very large amount of energy. Nowadays, one of the main aspects to be considered in textile processing is energy conservation. This target can be achieved by using microwave or ultrasound energies as effective and green approaches [1-13].

The first report use of ultrasound in textile dyeing was by Sokolov and Tumansky in 1941 [14]. The power of ultrasound enhance a wide variety of chemical processes, mainly due to the phenomenon known as cavitation in a liquid medium that is the growth and explosive collapse of microscopic bubbles which generate hot spots, i.e., localized high temperature, high pressure, shock waves and severe shear force capable of breaking chemical bonds [15]. High temperature and pressures resulting from the collapse of the transient cavitation bubbles are responsible for the observed effects of ultrasound [16]. Vouters et al. [17] reported that cavitation will allow accelerating processes and obtaining the same conventional results but with a lower dye and chemical concentrations and low temperature. Achievements obtained in dyeing processes by ultrasound might be attributed to dispersion, degassing and diffusion phenomena for ultrasound [18].

The present investigation aims at using microwave and ultrasound energy in dyeing process of polyester fabric using C.I. Disperse red 60 , as a way to enhance the dyeing process, in order to demonstrate that the energy is saved by using the microwave and ultrasound, the used dyeing temperatures are lower, dyeing is more improved, which is in accordance to preserve the environment.

\section{Material and Methods}

Fabric

Scoured and bleached $100 \%$ polyester fabric $\left(149 \mathrm{~g} / \mathrm{m}^{2}\right)$ was supplied by El-Mahalla El-Kobra Company.

Dye

C.I. Disperse red 60 supplied by DyeStar Company. Dispersing agents Matexil DA-N was supplied by ICI Company, commercial HC carrier supplied by Egyptian Turkish Co. for auxiliaries.

*Corresponding author e-mail: elapaserym@yahoo.com

DOI:10.21608/EJCHEM.2017.1478.1102

C2017 National Information and Documentation Center (NIDOC) 
<smiles>Nc1c(Oc2ccccc2)cc(O)c2c1C(=O)c1ccccc1C2=O</smiles>

C.I. Disperse Red 60

Dyeing

Conventional Dyeing

The dye baths were prepared from the dye ( $2 \%$ over weight of fabric) to a final liquor ratio of $40: 1, \mathrm{w} / \mathrm{w}$. The $\mathrm{pH}$ value of the bath was adjusted to $4.5-5$ in the presence of $2 \%$ of dispersing agent and $2 \%$ of carrier. The temperature was ranged from $60-80{ }^{\circ} \mathrm{C}$, and dyeing continued for $60 \mathrm{~min}$. After dyeing, the fabrics were thoroughly washed and then subjected to a surface reduction clearing [( $2 \mathrm{~g}$ sodium hydroxide and $2 \mathrm{~g}$ sodium hydrosulphite)/L]. The samples were heated in this solution for $30 \mathrm{~min}$. at $50{ }^{\circ} \mathrm{C}$ and then thoroughly washed and air-dried.

\section{Ultrasound Dyeing}

The dye baths were prepared from the dye ( $2 \%$ over weight of fabric) to a final liquor ratio of $40: 1, w / w$. The $\mathrm{pH}$ value of the bath was adjusted to 4.5-5 in the presence of dispersing agent ranged from $0-5 \%$, and $2 \%$ of carrier or without carrier. The temperature was ranged from $60-80{ }^{\circ} \mathrm{C}$ by using ultrasonic with power level 9 $(500 \mathrm{~W})$ (CREST Ultrasonic, TRU-SWEEPTM ultrasonic bench top cleaner bath, model 575 D with a capacity 5.751 ) and dyeing continued from $10-60 \mathrm{~min}$. The same post-treatment described in the conventional method was used here.

\section{Microwave Dyeing}

The dye baths were prepared from the dye (2\% over weight of fabric) to a final liquor ratio of $40: 1$, $\mathrm{w} / \mathrm{w}$. The $\mathrm{pH}$ value of the bath was adjusted to $4.5-$ 5 in the presence of dispersing agent ranged from $0-5 \%$, and $2 \%$ of carrier or without carrier. The temperature was ranged from $60-80{ }^{\circ} \mathrm{C}$ by using focused microwave oven (CEM Mars microwave, Matthews, NC, USA) and dyeing continued from 10-60 min. The same post-treatment described in the conventional method was used here.

\section{High Temperature Dyeing}

The dye baths were prepared from the dye ( $2 \%$ over weight of fabric) to a final liquor ratio of $40: 1, \mathrm{w} / \mathrm{w}$. The $\mathrm{pH}$ value of the bath was adjusted to $4.5-5$ in the presence of $2 \%$ of dispersing agent. The temperature was raised to $130{ }^{\circ} \mathrm{C}$ by using IR dyeing machine, and dyeing continued for $60 \mathrm{~min}$. The same post-treatment described in the conventional method was used here.

\section{Testing and analysis \\ Colour Measurements}

The colorimetric parameters of the dyed polyester fabrics (Tables 1-4) were measured on a reflectance spectrophotometer. The color yields of the dyed samples were measured by using the light reflectance technique performed on an UltraScan PRO D65 UV/VIS Spectrophotometer. The color strengths, expressed as K/S values, were measured by applying the Kubelka-Munk equation.

$$
\mathrm{K} / \mathrm{S}=(1-\mathrm{R})^{2} / 2 \mathrm{R}
$$

where: $\mathrm{R}$ is the reflectance of colored samples and $\mathrm{K}$ and $\mathrm{S}$ are the absorption and scattering coefficients, respectively. Summation method ( $\Sigma$ $(\mathrm{K} / \mathrm{S}) \lambda)$ was used for an equally spaced selection of wavelength in range of 350-750 nm.

\section{CIE Lab Difference}

$$
\Delta \mathrm{E}=\left[\left(\mathrm{L}^{2}+\mathrm{a}^{2}+\mathrm{b}^{2}\right)\right]^{1 / 2}
$$

$\Delta \mathrm{E}$ : the total color difference between the sample and the standard: L represents the whiteblack axis, a represents the red-green axis and finally $\mathrm{b}$ represents the yellow-blue axis.

\section{Fastness Properties}

Fastness properties of the dyed samples were tested to rubbing, perspiration, washing and light fastness according to AATCC standard tests [19-22].

\section{Results and Discussions}

Effect of dyeing temperatures of conventional, ultrasound and microwave on the $K / S$ value of polyester fabric dyed by using a carrier

It is of value to mention here that figure 1 shows that as the dyeing temperature increases from $60-80{ }^{\circ} \mathrm{C}$, the $\mathrm{K} / \mathrm{S}$ values increases for conventional, ultrasound and microwave dyeing, that might be attributed to the high distribution rate and also to the increase in the kinetic energy of the dye molecules [23].

Increasing $\mathrm{K} / \mathrm{S}$ values of the microwave and ultrasound dyeing compared to the conventional dyeing may be attributed to the fact that, microwave and ultrasound waves facilitating a dye-fiber contact and accelerating the rate of diffusion of the dye inside the fiber by breaking the boundary layers covering the fiber and raising the interaction between dye molecules and fibers through cavitation phenomenon [24].

The measured K/S given by the reflectance spectrometer directly correlated with the dye concentration on the dye substrate. The color 
coordinates listed in Table 1 indicate that the dye has good affinity to polyester fabric at the given temperatures and gave bright and intense red hue. The colors of the dyed samples by microwave or ultrasound irradiations are deeper than the same samples dyed by the same dye using the conventional dyeing methods. This trend is explained by the higher values of (a) in the former case compared to that in the latter case, as shown in Table 1.

Effect of concentration of dispersing agent on the $K / S$ value of dyeing polyester fabric using carrier

Figure 2, shows the relationship between $\mathrm{K} / \mathrm{S}$ as a parameter for dye uptake and the concentrations of the dispersing agent used from 0 to $5 \%$ present in the dyebath, in the beginning the $\mathrm{K} / \mathrm{S}$ values increase with increasing the amount of dispersing agent applied from 0 to $1 \%$ after that the $\mathrm{K} / \mathrm{S}$ values decrease with increasing the amount of dispersing agent. These results revealed that this dye is in the nano size before irradiation, for this reason this dye shows excellent distribution of its particles at high temperature dyeing method $(\mathrm{K} / \mathrm{S}=14.20)$.

Effect of dyeing time of microwave and ultrasound on the $K / S$ value

It is clear from Fig. 3 that in the presence of carrier, increasing time of irradiations from 10-60 min leads to increase in $\mathrm{K} / \mathrm{S}$ values that are because of the microwave and ultrasound irradiations which take place for reducing the particle size, consequently the problem of agglomeration is minimized

In the light of the above results, it appears that microwave supported dyeing on polyester, in the absence of carrier, are actually better than when the carrier is included in the system. It is apparent from figure 4 that increasing microwave irradiation time from 10 minutes to 60 minutes leads to higher color yields $(\mathrm{K} / \mathrm{S})$ on the polyester fabric.

Fastness properties

The overall evaluations of the fastness assessment of the obtained color on the polyester fabrics regarding the applied method is given in Table 5. The obtained results showed that polyester dyed fabrics (treated with microwave or ultrasound energy) have a greater fastness levels to (rubbing, perspiration, washing and light) than the conventional dyeing; this might be attributed to the fact that microwave and ultrasound irradiations increase penetration.

TABLE 1. Effect of dyeing temperatures on the K/S value.

\begin{tabular}{|c|c|c|c|c|c|c|c|}
\hline Temperature $^{\circ} \mathrm{C}$ & $\mathbf{K} / \mathbf{S}$ & $\mathbf{L}$ & $\mathbf{a}$ & b & c & $\mathbf{h}$ & $\Delta \mathbf{E}$ \\
\hline \multicolumn{8}{|c|}{ Conventional dyeing } \\
\hline 60 & 1.03 & 64.56 & 26.07 & -5.75 & 26.70 & 347.56 & 69.86 \\
\hline 65 & 1.17 & 65.77 & 24.57 & -6.02 & 25.29 & 346.24 & 70.46 \\
\hline 70 & 1.51 & 62.06 & 30.34 & -6.05 & 30.94 & 348.72 & 69.34 \\
\hline 75 & 2.43 & 57.61 & 37.79 & -5.53 & 38.20 & 351.68 & 69.13 \\
\hline 80 & 3.95 & 53.24 & 44.80 & -4.45 & 45.02 & 354.32 & 69.72 \\
\hline \multicolumn{8}{|c|}{ Ultrasound dyeing } \\
\hline 60 & 2.15 & 57.44 & 33.06 & -5.93 & 33.59 & 349.84 & 66.54 \\
\hline 65 & 2.93 & 52.78 & 34.37 & -6.59 & 35.00 & 349.14 & 63.33 \\
\hline 70 & 4.87 & 49.11 & 42.69 & -4.84 & 42.96 & 353.52 & 65.25 \\
\hline 75 & 8.68 & 44.23 & 49.29 & -1.29 & 49.31 & 358.50 & 66.29 \\
\hline 80 & 7.61 & 45.8 & 49.41 & -2.39 & 49.47 & 357.23 & 67.41 \\
\hline \multicolumn{8}{|c|}{ Microwave dyeing } \\
\hline 60 & 5.46 & 49.45 & 47.33 & -3.67 & 47.98 & 355.57 & 58.55 \\
\hline 65 & 5.60 & 49.39 & 47.33 & -3.29 & 47.44 & 356.03 & 68.48 \\
\hline 70 & 12.90 & 42.69 & 54.25 & 1.34 & 54.28 & 1.96 & 69.06 \\
\hline 75 & 14.01 & 41.12 & 54.50 & 2.66 & 54.56 & 2.79 & 68.32 \\
\hline 80 & 15.40 & 40.45 & 54.77 & 3.42 & 54.88 & 3.58 & 68.18 \\
\hline \multicolumn{8}{|c|}{ High temperature dyeing } \\
\hline 130 & 14.20 & 41.56 & 55.52 & 3.18 & 55.61 & 3.28 & 69.42 \\
\hline
\end{tabular}




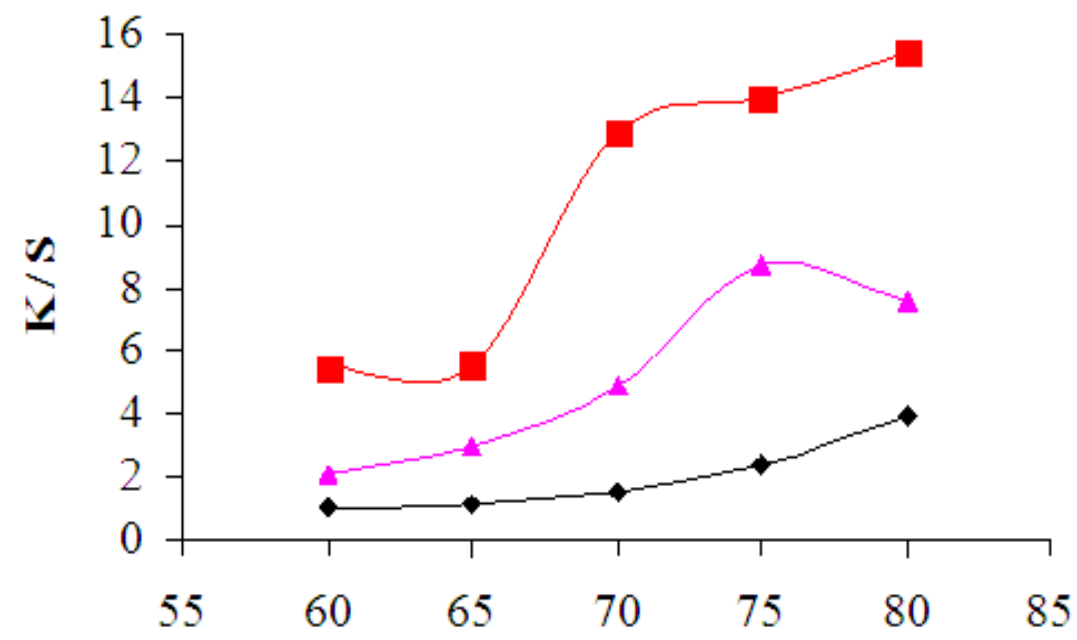

Temperature of dyeing

Dye $2 \%$ (o.w.f) at $60-80^{\circ} \mathrm{C}$ with $1: 40$ liquor ratio at $\mathrm{pH} 4.5-5$, conc. of carrier $2 \%$ (o.w.f), dispersing agent $2 \%$ (o.w.f) for 1 hour.

Fig. 1. Effect of dyeing temperatures on the K/S value.

TABLE 2. Effect of concentration of dispersing agent on the $\mathrm{K} / \mathrm{S}$ value.

\begin{tabular}{|c|c|c|c|c|c|c|c|}
\hline $\begin{array}{c}\text { Concentration of } \\
\text { dispersing agent } \%\end{array}$ & $\mathbf{K} / \mathbf{S}$ & $\mathbf{L}$ & a & b & c & $\mathbf{h}$ & $\Delta \mathbf{E}$ \\
\hline \multicolumn{8}{|c|}{ Ultrasound dyeing at $75^{\circ} \mathrm{C}$} \\
\hline 0 & 4.40 & 53.80 & 51.21 & -3.66 & 51.34 & 355.92 & 74.36 \\
\hline 0.25 & 5.60 & 51.43 & 53.61 & -1.87 & 53.64 & 358.00 & 74.31 \\
\hline 0.50 & 7.03 & 47.52 & 51.54 & -1.27 & 51.65 & 352.59 & 70.18 \\
\hline 1 & 8.68 & 44.23 & 49.29 & -1.29 & 49.31 & 358.50 & 66.29 \\
\hline 2 & 7.32 & 47.84 & 49.33 & -2.86 & 49.41 & 356.68 & 68.78 \\
\hline 3 & 6.76 & 47.29 & 49.74 & -2.71 & 49.81 & 356.88 & 68.69 \\
\hline 4 & 7.00 & 47.90 & 49.35 & -2.98 & 49.44 & 356.54 & 68.84 \\
\hline 5 & 6.73 & 48.17 & 48.99 & -3.45 & 49.11 & 355.97 & 68.79 \\
\hline \multicolumn{8}{|c|}{ Microwave dyeing at $80^{\circ} \mathrm{C}$} \\
\hline 0 & 14.40 & 43.24 & 54.19 & 4.34 & 59.38 & 4.67 & 73.46 \\
\hline 0.25 & 14.50 & 42.74 & 59.33 & 3.82 & 58.46 & 3.74 & 72.42 \\
\hline 0.50 & 15.03 & 42.79 & 59.09 & 4.77 & 59.28 & 4.62 & 73.11 \\
\hline 1 & 15.40 & 40.45 & 54.77 & 3.42 & 54.88 & 3.58 & 68.18 \\
\hline 2 & 12.60 & 42.33 & 53.88 & 1.70 & 53.91 & 1.81 & 68.54 \\
\hline 3 & 13.10 & 42.28 & 54.88 & 2.12 & 55.00 & 2.20 & 69.38 \\
\hline 4 & 14.40 & 41.53 & 54.56 & 2.67 & 54.62 & 2.80 & 68.62 \\
\hline 5 & 13.60 & 42.11 & 54.71 & 2.15 & 54.75 & 2.25 & 68.07 \\
\hline
\end{tabular}






Dye $2 \%$ (o.w.f) at $75{ }^{\circ} \mathrm{C}$ for ultrasound and at $80{ }^{\circ} \mathrm{C}$ for microwave with 1:40 liquor ratio at $\mathrm{pH} \quad 4.5-5$, conc. of carrier $2 \%$ (o.w.f), .dispersing agent $1-5 \%$ (o.w.f) for 1 hour

Fig. 2. Effect of concentration of dispersing agent on the K/S value.

TABLE3.Effectofdyeingtimeof microwaveand ultrasound on theK/Svalueofdyeingpolyesterfabricwith usingcarrier

\begin{tabular}{|c|c|c|c|c|c|c|}
\hline Time (min.) & $\mathbf{K} / \mathbf{S}$ & $\mathbf{L}$ & a & $\mathbf{b}$ & c & $\Delta \mathbf{E}$ \\
\hline \multicolumn{7}{|c|}{ Ultrasound dyeing at $75^{\circ} \mathrm{C}$} \\
\hline 10 & 1.56 & 61.65 & 33.14 & -6.45 & 33.76 & 348.99 \\
\hline 20 & 4.00 & 51.70 & 41.53 & -4.89 & 41.82 & 353.28 \\
\hline 30 & 4.44 & 50.55 & 43.15 & -4.79 & 43.41 & 353.66 \\
\hline 40 & 5.34 & 49.19 & 46.09 & -3.96 & 46.26 & 355.09 \\
\hline 50 & 7.00 & 46.08 & 47.46 & -3.05 & 47.56 & 356.32 \\
\hline 60 & 8.68 & 44.23 & 49.29 & -1.29 & 49.31 & 358.50 \\
\hline
\end{tabular}

Microwave dyeing at $80^{\circ} \mathrm{C}$

$\begin{array}{lllllll}10 & 11.24 & 43.53 & 54.47 & 0.31 & 54.47 & 69.73 \\ 20 & 11.70 & 43.20 & 54.69 & 0.81 & 54.70 & 69.70 \\ 30 & 12.46 & 43.40 & 55.36 & 1.07 & 55.37 & 70.35 \\ 40 & 13.19 & 42.71 & 54.99 & 1.61 & 55.01 & 69.65 \\ 50 & 14.68 & 42.07 & 55.24 & 2.48 & 55.30 & 69.48\end{array}$




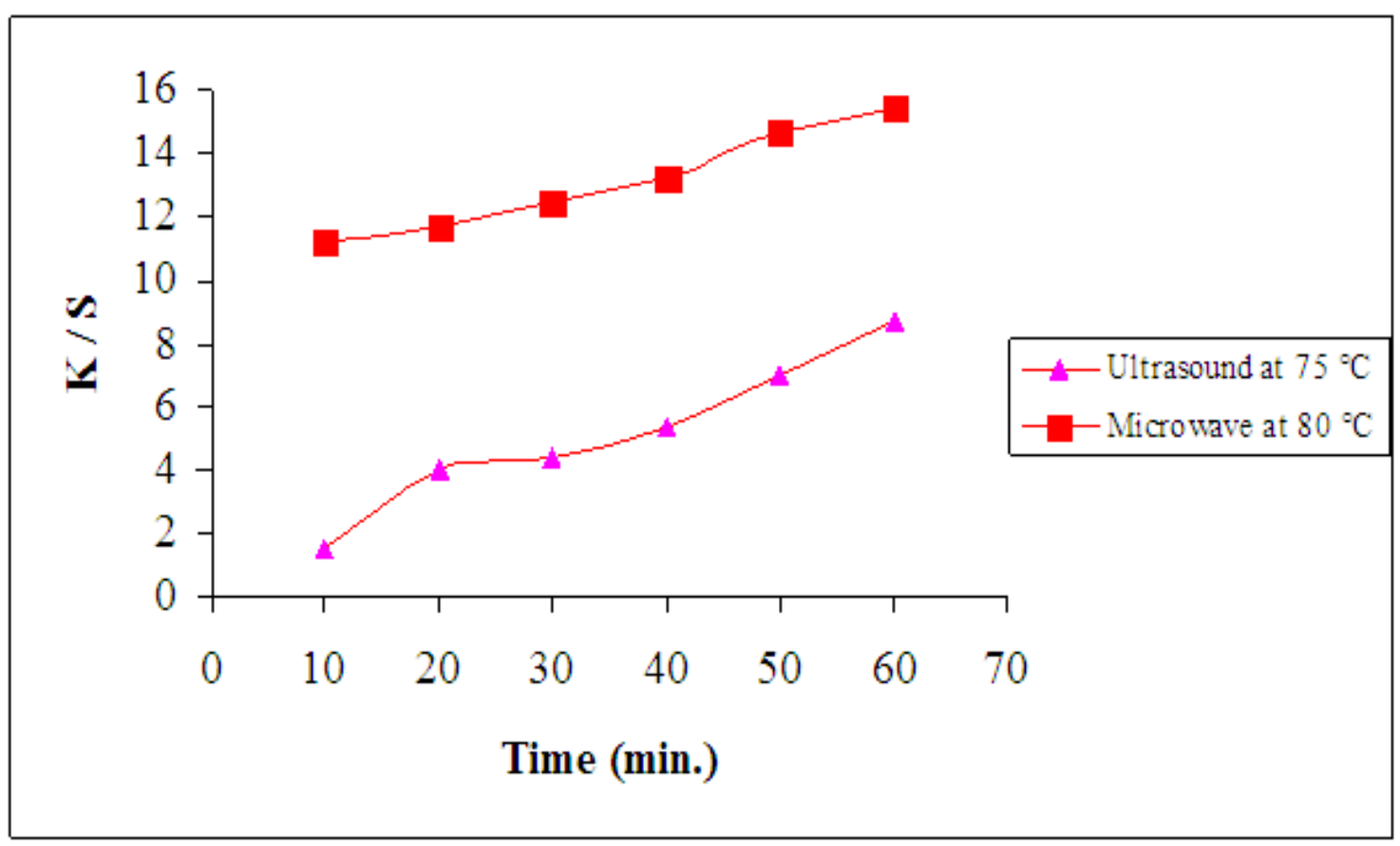

Fig. 3. Effect of dyeing time of microwave and ultrasound on the K/S value of dyeing polyester fabric with using carrier.

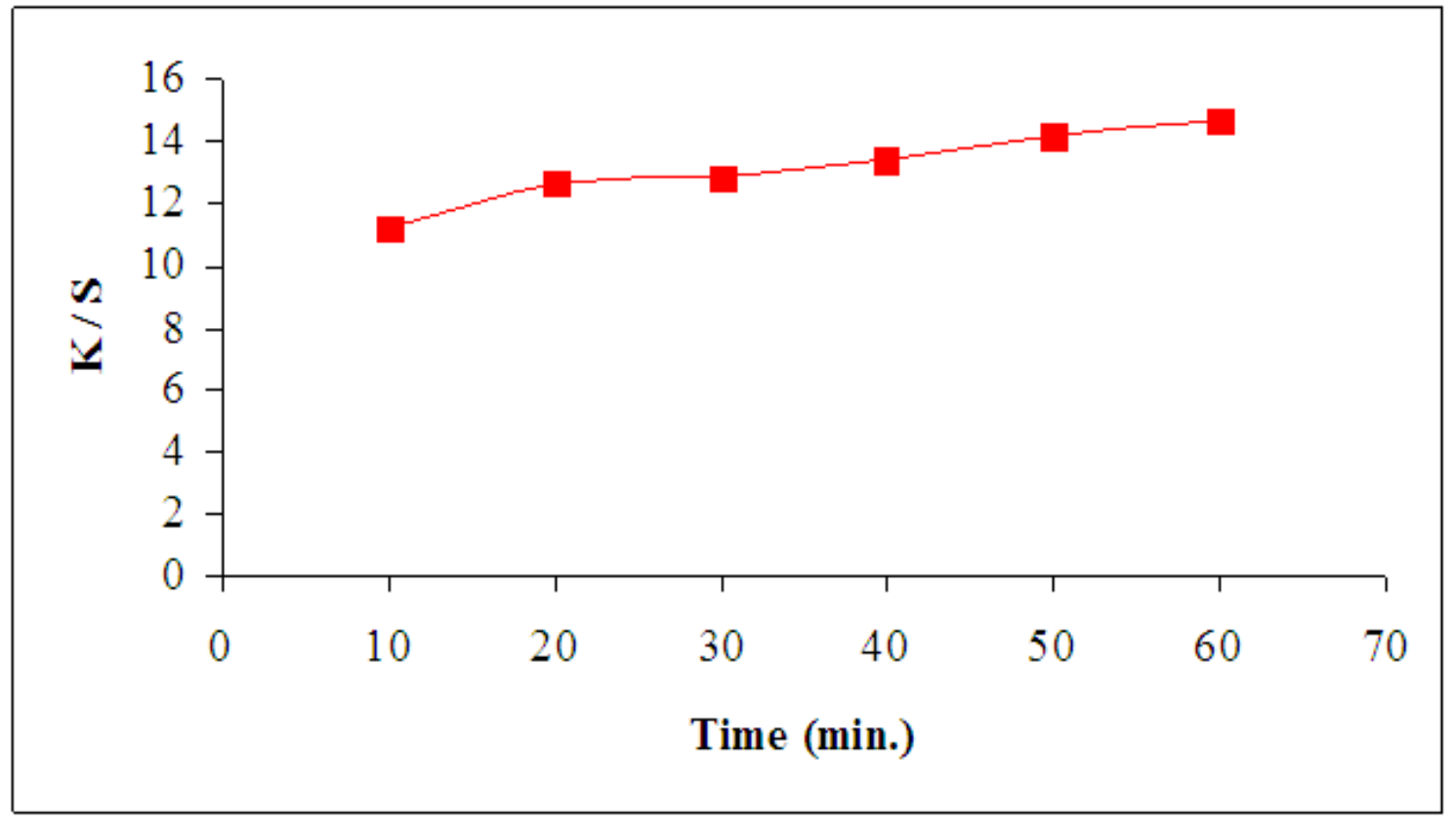

Dye $2 \%$ (o.w.f) at $75^{\circ} \mathrm{C}$ with 1:40 liquor ratio at $\mathrm{pH} 4.5-5$, conc. of carrier $0 \%$ (o.w.f), dispersing agent $2 \%$ (o.w.f) for 10-60 min.

Fig. 4. Effect of dyeing time of microwave on the $\mathrm{K} / \mathrm{S}$ value of dyeing polyester fabric without using carrier. 
TABLE 4. Effect of dyeing time of microwave on the K/S value of dyeing polyester fabric without using carrier.

\begin{tabular}{ccccccccc}
\hline Time (min.) & K/S & $\mathbf{L}$ & $\mathbf{a}$ & $\mathbf{b}$ & $\mathbf{c}$ & $\mathbf{h}$ & $\Delta \mathbf{E}$ \\
& & & & & & & & \\
\hline 10 & 11.21 & 43.82 & 54.74 & 0.52 & 54.74 & 0.54 & 70.12 \\
20 & 12.60 & 44.74 & 59.66 & 3.68 & 59.77 & 3.53 & 74.66 \\
30 & 12.80 & 43.28 & 59.18 & 3.97 & 58.94 & 3.86 & 73.60 \\
40 & 13.40 & 41.36 & 58.48 & 4.28 & 58.64 & 4.19 & 72.88 \\
50 & 14.20 & 41.56 & 55.52 & 3.18 & 55.61 & 3.28 & 69.42 \\
60 & 14.70 & 42.63 & 59.37 & 4.79 & 59.57 & 4.62 & 73.25 \\
\hline
\end{tabular}

TABLE 5. Fastness properties of dyed polyester fabric.

\begin{tabular}{|c|c|c|c|c|c|c|c|c|c|c|c|c|c|c|c|}
\hline \multirow{4}{*}{$\begin{array}{l}\text { Dyeing } \\
\text { method }\end{array}$} & \multicolumn{15}{|c|}{ Fastness properties } \\
\hline & \multirow{2}{*}{\multicolumn{2}{|c|}{ Rubbing }} & \multicolumn{8}{|c|}{ Perspiration } & \multirow{2}{*}{\multicolumn{4}{|c|}{ Washing }} & \multirow{3}{*}{$\begin{array}{l}\text { Light } \\
\text { fastness }\end{array}$} \\
\hline & & & \multicolumn{4}{|c|}{ Acid } & \multicolumn{4}{|c|}{ Alkali } & & & & & \\
\hline & Dry & Wet & $\mathbf{A}$ & $\mathrm{C}$ & W & $\bar{P}$ & $\bar{A}$ & $\mathrm{C}$ & W & $\bar{P}$ & $\mathrm{~A}$ & $\mathrm{C}$ & W & $\overline{\mathrm{P}}$ & \\
\hline Conventional dyeing & 4 & 4 & $4-5$ & $4-5$ & $4-5$ & $4-5$ & 4 & $4-5$ & $4-5$ & 4 & 4 & $4-5$ & $3-4$ & $3-4$ & $3-4$ \\
\hline $\begin{array}{l}\text { Ultrasound dyeing } \\
\text { without carrier }\end{array}$ & 4 & 4 & $4-5$ & $4-5$ & $4-5$ & 4 & 4 & 4 & $4-5$ & 3-4 & 4 & $4-5$ & $4-5$ & 4 & 4 \\
\hline $\begin{array}{l}\text { Ultrasound dyeing } \\
\text { with carrier }\end{array}$ & 4 & $3-4$ & 4 & 4 & $3-4$ & 4 & 4 & 4 & 4 & 4 & 4 & $4-5$ & 4 & $3-4$ & $4-5$ \\
\hline $\begin{array}{l}\text { Microwave dyeing } \\
\text { without carrier }\end{array}$ & 4 & $3-4$ & 4 & $4-5$ & $4-5$ & 4 & $4-5$ & $4-5$ & $4-5$ & $4-5$ & $4-5$ & $4-5$ & $4-5$ & $4-5$ & 5 \\
\hline $\begin{array}{c}\text { Microwave dy eing } \\
\text { with carrier }\end{array}$ & 4.5 & 4 & 4 & $4-5$ & $4-5$ & 4 & 4 & $4-5$ & $4-5$ & 4 & 4 & $4-5$ & $4-5$ & 4 & 5 \\
\hline $\begin{array}{l}\text { High temperature } \\
\text { dyeing }\end{array}$ & 4 & 4 & $4-5$ & $4-5$ & $4-5$ & $4-5$ & $4-5$ & $4-5$ & $4-5$ & $4-5$ & 4 & $4-5$ & $4-5$ & 4 & 5 \\
\hline
\end{tabular}

Where: $\mathrm{A}=$ Alteration, $\mathrm{C}=$ Staining on cotton, $\mathrm{W}=$ Staining on wool, $\mathrm{P}=$ Staining on polyester

\section{Conclusion}

Color strength $\mathrm{K} / \mathrm{S}$ and CIE Lab color space parameters exhibited a significant increment by using ultrasound and microwave dyeing methods. The obtained results in this study showed higher fastness properties to rubbing, perspiration, washing and light than the conventional dyeing. Also, using ultrasound and microwave radiation to support the dyeing of polyester with C.I. Disperse Red 60, gives important energy savings since dyeing temperature is reduced from $130{ }^{\circ} \mathrm{C}$ to $80{ }^{\circ} \mathrm{C}$ and additionally the new process gives better dye uptake.

\section{Acknowledgment}

The authors are very gratefully to the late Dr. Zain Mahmoud for his facilitating work on the equipment of microwave for this study. The authors are gratefully to the late Prof. Dr. Mona Kamel for her effective advisements through this work.

\section{$\underline{\text { References }}$}

1. Peters D. Ultrasound in materials chemistry. Journal of Materials Chemistry, 6 (10), 1605-18 (1996).

2. Kappe C.O., Controlled Microwave Heating in Modern Organic Synthesis. Angew. Chem. Int. Ed. 43, 6250-6284 (2004).

3. El-Apasery M.A., Synthesis of some azo disperse dyes by the use of focused microwave heating. Pol. J. Appl. Chem., 50, 75-81 (2006).

4. Al-Mousawi S., Elassar A-Z. and El-Apasery M.A.A, Microwave assisted diazo coupling reaction : The synthesis of alkyl azines and thienopyridazines. phosphorus. Sul. Sil. Rel. Elem., 181, 1755-1771 (2006).

5. El-Apasery M.A., Solvent-free one-pot synthesis of some azodisperse dyes under microwave irradiation: Dyeing of polyester fabrics. J. Appl. 
Polym. Sci., 109, 695-699 (2008).

6. Al-Etaibi A.M., El-Apasery M.A., Ibrahim M.R. and Al-Awadi N.A., A facile synthesis of new monoazo disperse dyes derived from 4-hydroxyphenylazopyrazole-5-amines: evaluation of microwave assisted dyeing behavior. Molecules, 17, 13891-13909 (2012).

7. Oner E., Buyukakinci Y. and Sokmen N., Microwaveassisted dyeing of poly(butylene terephthalate) fabrics with disperse dyes. Color. Technol. 129, 125-130 (2013).

8. Al-Etaibi A.M., El-Apasery M.A., Huda H.M. and Al-Awadi N.A., One-pot synthesis of disperse dyes under microwave irradiation: Dyebath reuse in dyeing of polyester fabrics. Molecules, 17, 42664280 (2012).

9. Al-Qalaf F., Almohammad K., El-Apasery M.A. and Mahmoud H., Synthesis of some biologically active monoazo disperse dyes derived from nicotinic acid derivatives under microwave irradiation for dyeing polyester fabrics. Eur. J. Chem., 4, 211-215(2013).

10. El-Molla M.M., Haggag K., El-Shall F.N. and Shaker N.O., Part 1: Synthesis and evaluation of novel nano scale powdered polyurethane acrylate binders. Advances in Chemical Engineering and Science, 2(2), 212-227(2012).

11. Abou El-Kheir, A., Haggag, K., Mowafi and S.I., El-Sayed, H., Microwave-assisted beaching of wool fabrics. Journal of Natural Fibers, 12(2), 97107(2015).

12.Haggag K., El-Molla M.M., Shake N.O., Alian N. A. and El-Shall F. N., Use of the novel synthesized aqueous binders for pigment printing cotton fabrics using three modes of fixation. International Journal of Textile Science, 1(6), 49-61(2012).

13. Kappe C.O. and Dallinger D., Controlled microwave heating in modern organic synthesis: highlights from the 2004-2008 literature. Mol. Divers. 13, 71-193 (2009).

14. Vajnhandl S., and Le Marechal A.M., Ultrasound in textile dyeing and the decoloration/ mineralization of textile dyes, Dyes and Pigments, $\mathbf{6 5}(2), 89-101(2005)$.

15. Kamel M.M., El-Shishtawy R.M., Yussef B.M. and Mashaly H., Ultrasonic assisted dyeing III. Dyeing of wool with lac as a natural dye, Dyes and Pigments, 65(2), 103-110(2005).

16.Moholkar V.S., Rekveld S. and Warmoeskerken M.M.C.G., Modeling of the acoustic pressure fields and the distribution of The cavitation phenomena in a dual frequency sonic processor. Ultrasonics, 38, 666-670(2000).

17. Vouters M., Rumeau P., Tierce P. and Costes S., Ultrasounds: An industrial solution to optimize costs, environmental requests and quality for textile finishing., Ultrasonics Sonochemistry, 11, 3338(2004).

18. Kamel M.M., El-Shistawy R.M., Hana H.L. and Ahmed N.S.E., Ultrasonic-assisted dyeing: I. Nylon dyeability with reactive dyes. Polymer International, 52 (3), 373-380(2003).

19. AATCC, Technical Manual, Method 15 (1989), 68, 30-32 (1993).

20. AATCC, Technical Manual, Method 36 (1972), 68 (1993).

21. AATCC, Technical Manual, Method 8 (1989), 68, 23-25 (1993).

22. AATCC, Technical Manual, Method 16 A (1988), 68, 33-48 (1993).

23. Mashaly H. M., Abdelghaffar R. A., Kamel M. M. and Youssef B. M., Dyeing of polyester fabric using nano disperse dyes and improving their light fastness using $\mathrm{ZnO}$ nano powder. Indian Journal of Science and Technology, 7(7), 960-967(2014).

24. Abou Elmaaty T., Elnagar K., Hassan S. and Gamal H., Antibacterial activity and dyeing characteristics of some azo-pyazole disperse dyes using ecofriendly ultrasound energy for PET fabric. International Journal of Scientific \& Engineering Research, 5(5), 1156-1161(2014).

(Received 13/8/2017; aacepted 15/10/2017) 
الصباغة بمساعدة الميكروويف ، الموجات فوق الصوتية جزء 1اء 1: الخصائص الصباغية

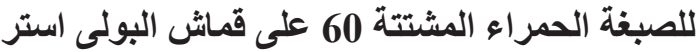



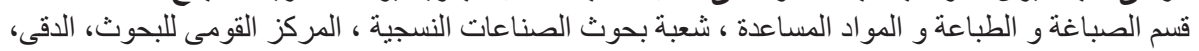

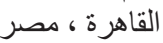

كان الهدف من هذه الدراسة استخدام أثنعة الميكروويف و التشعيع بالموجات فوق الصوتية كمنهجية خضر اءو، الطباء

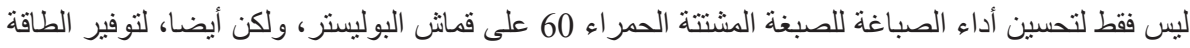

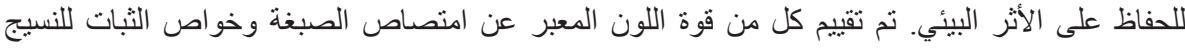
المصبوغ. 